\title{
Linking Covalent Histone Modifications to Epigenetics: The Rigidity and Plasticity of the Marks
}

\author{
Y. WANG, ${ }^{* \dagger}$ J. WySOCKA, ${ }^{* \dagger}$ J.R. PERLIN, ${ }^{*}$ L. LEONELLI, \\ C.D. ALLIS, ${ }^{\dagger}$ AND S.A. COONROD" \\ *Department of Genetic Medicine, Weill Medical College of Cornell University, New York, New York 10021; \\ ${ }^{\dagger}$ Laboratory of Chromatin Biology, The Rockefeller University, New York, New York 10021
}

In higher eukaryotes, genetic information, encoded by the DNA double helix, is organized into a complex chromatin structure with the assistance of histone and nonhistone proteins. As such, chromatin is the physiologically relevant form of eukaryotic genomes. While it is largely uncontested that different genetic compositions of individual species underlie their unique physiology and final morphology, chromatin provides an additional layer for dictating the translation of genetic information into meaningful biological readouts (for review, see Strahl and Allis 2000; Jenuwein and Allis 2001; Felsenfeld and Groudine 2003). Increasing evidence underscores an emerging theme in biology wherein "epigenetic" mechanisms, defined as mechanisms operating outside of changes in DNA sequence, govern gene function by creating potentially heritable alternative states of chromatin. DNA methylation and covalent modifications of histones, such as methylation, acetylation, and phosphorylation, are thought to contribute to these chromatin states by serving as a platform that integrates cell differentiation signals and environmental cues as well as regulating the timely release of the appropriate genetic information (Cheung et al. 2000; Schreiber and Bernstein 2002). Several of the above histone modifications are readily reversible through enzymatic means; others are potentially static (Bannister et al. 2002; see below). One central problem that remains to be resolved is how these mechanisms are regulated either during normal developmental conditions or under various pathological conditions.

\section{EPIGENETIC MECHANISMS UNDERLYING DIFFERENTIATION DURING MAMMALIAN EMBRYONIC DEVELOPMENT}

Gametogenesis gives rise to two different types of terminally differentiated cells, the sperm and the egg, which fuse during fertilization to initiate a new life cycle. During early developmental stages, the zygote and the blastomeres in two-, four-, and eight-cell embryos are totipotent, meaning that they possess an unrestricted developmental potential and are capable of differentiating into all cell types (Matzuk and Lamb 2002; SassoneCorsi 2002). By the 16-cell stage, a gradual restriction in the developmental potential of cells takes place resulting in the production of two distinct lineages: (1) the trophectoderm, which eventually develops into the extraembryonic tissues; and (2) the inner cell mass, which develops into the embryo proper. The inner cell mass then gives rise to ectoderm, endoderm, and mesoderm. These different germ layers further develop and are organized to form various somatic tissues and organs (Fig. 1). This developmental process is associated with dramatic changes in gene expression profiles and is often referred to as cellular differentiation.

While mechanisms underlying the differentiation process remain unclear, several lines of evidence suggest the involvement of epigenetic regulation (as defined above; Kelly and Trasler 2004). For example, nuclear cloning experiments show that the developmental potential of a terminally differentiated somatic cell nucleus can be

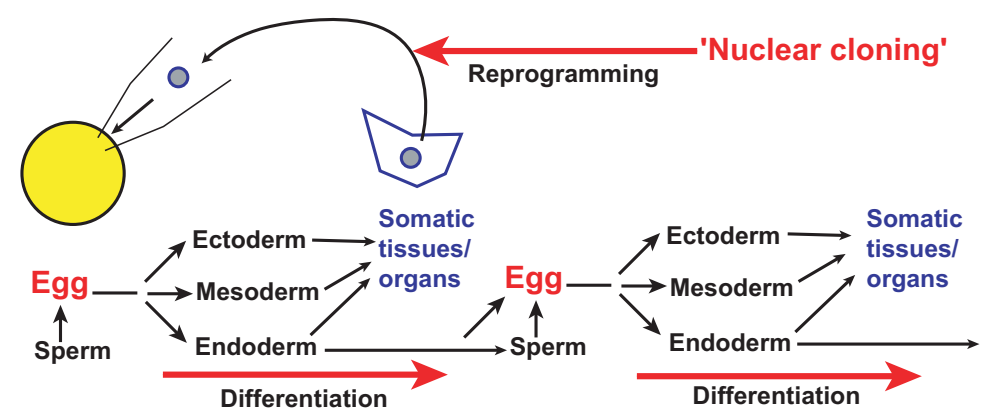

Figure 1. Cell differentiation is based on epigenetic mechanisms. Differentiation, germ layer (ectoderm, endoderm, or mesoderm) formation, and organogenesis in a developing embryo are associated with heritable changes in gene expression profiles. However, the change of gene expression is caused not by the changes in the genetic information per se, but by epigenetic mechanisms. This notion is strongly supported by animal cloning experiments, which also suggest that eggs are rich with machineries capable of erasing the epigenetic information of a somatic nucleus. 
fully restored to totipotency following transfer into an enucleated egg (Campbell et al. 1996; Wakayama et al. 1998). However, the low success rate of cloning (1-3\% for adult somatic cell nuclei and $10-30 \%$ for embryonic nuclei) and the high rate of developmental defects associated with cloning strongly argue that epigenetic information carried by the transferred nucleus can be reprogrammed only on a limited basis (Hiendleder et al. 2004). On the other hand, these experiments suggest that poorly defined machinery stored in the egg is capable of reversing the biological clock back to its primary state. Identification of these suspected regulatory factors and the elucidation of their role during normal and abnormal developmental processes would offer important insights toward our understanding of epigenetic regulation of gene activity.

\section{FUNDAMENTAL ROLES OF HISTONES IN ORCHESTRATING THE EPIGENETIC INFORMATION}

The nucleosome is the basic structural unit of chromatin, consisting of about 146 bp of DNA wrapped around an octamer of core histones (including two each of histone H3, H4, H2B, and H2A) (van Holde 1989; Luger et al. 1997). Nucleosomal arrays are further stabilized by members of the linker histone $\mathrm{H} 1 / \mathrm{H} 5$ family whose precise roles in chromatin function remains unclear (Wolffe 1998). While initially thought to be an inert structure involved in packaging DNA into the confines of the nucleus, significant progress has been made in documenting a more dynamic view of chromatin, particularly during transcriptional activation and repression (for review, see Felsenfeld and Groudine 2003; Khorasanizadeh 2004). This includes experiments with test "designer" genes where remarkable transitions between decondensed and condensed chromatin have been documented in living cells (Strukov et al. 2003; Janicki et al. 2004).

While there are many ways to introduce physiologically relevant variation into the chromatin polymer (Felsenfeld and Groudine 2003), numerous reports have documented that covalent histone modifications, working in a sequential and/or combinatorial manner, regulate DNA and chromatin templated cellular events, such as gene expression, DNA repair, and chromosome condensation (see Strahl and Allis 2000; Jenuwein and Allis 2001; Fischle et al. 2003). Well-documented histone modifications include acetylation, methylation, phosphorylation, ubiquitination, and ADP-ribosylation (for reviews, see Grunstein 1997; Cheung et al. 2000; Roth et al. 2001; Zhang and Reinberg 2001; Kouzarides 2002; Lachner et al. 2003). Other modifications, such as sumoylation (Shiio and Eisenman 2003), or the newly discovered citrullination (Hagiwara et al. 2002; this paper), are less well understood, but are likely to play key regulatory roles that will require further study. Although it remains unclear as to whether a true "histone code" exists, and, if so, the precise form and extent to which it is utilized (Agalioti et al. 2002; Schreiber and Bernstein 2002; Kurdistani et al. 2004; Schubeler et al. 2004), this hypothesis offers a useful framework for the study of histone modifications, modifying enzymes, and effector proteins, as well as the role of these machineries and pathways in regulating important cellular functions.

\section{HISTONE METHYLATION: STORIES OF Lys AND Arg}

For the purpose of the discussion below, we highlighted several relevant modification sites in histone $\mathrm{H} 3$ and $\mathrm{H} 4$ in Figure 2A. Methylation of histone Lys residues, which can be mono-, di-, or trimethyl, is associated with actively expressed genes, as well as with silenced genes or large heterochromatin regions. For example, methylation at Lys4 and Lys79 of H3 is often found to be associated with actively expressed genes (Strahl et al. 1999; Santos-Rosa et al. 2003; Schubeler et al. 2004). On the other hand, methylation at Lys9 and Lys27 of H3 is closely correlated with the formation of repressive chromatin structure at both centromeric regions and silenced genes such as homoetic genes (for references, Schubeler et al. 2004; see below). Multiple histone H3 Lys9 methyltransferases have been reported, including G9a, Suv39h1, h2, and ESET (for review, see Lachner et al. 2003). Mice carrying mutations of these enzymes die at early embryonic stages (Peters et al. 2001; Dodge et al. 2004). EZH2, the well-studied methyltransferase of H3 Lys27, is also important for early mouse embryonic development (Erhardt et al. 2003). These results indicate that "setting" the epigenetic marks of histone Lys methylation ensures the normal embryonic development.

In addition to Lys methylation, protein arginine methyltransferases (PRMTs) modify multiple Arg residues in the amino-terminal tails of H3 and H4 (Fig. 2A). PRMT1 methylates histone $\mathrm{H} 4 \mathrm{Arg} 3$ residues, while histone $\mathrm{H} 3$ Arg17 is a preferred target site for CARM1 (Strahl et al. 2001; Wang et al. 2001; Bauer et al. 2002). Furthermore, methylation of Arg residues in H3 and H4 functions synergistically with histone Lys acetylation during activation of nuclear hormone regulated genes (Wang et al. 2001; Daujat et al. 2002). Recently, it was found that PRMT1, CARM1, and histone acetyltransferase p300 cooperate with p53 to activate gene expression (An et al. 2004). Taken together, these studies suggest that Arg methylation of histones is intimately involved in gene activation from chromatin templates.

\section{CROSS-TALK OF DNA METHYLATION AND Lys METHYLATION IN HISTONES}

For many years, DNA methylation, namely the 5methylcytosine $(5 \mathrm{mC})$ modification at $\mathrm{CpG}$ islands of the genome, has been the main focus of the epigenetic gene regulation field (for review, see Jaenisch and Bird 2003; Feinberg and Tycko 2004). The findings that histone modifications can regulate DNA methylation patterns suggest that histone modifications, particularly Lys methylation, are important regulatory mechanisms of epigenetic phenomena, such as X-chromosome inactivation, imprinting, and cancer etiology. In Neurospora crassa, DIM5, a methyltransferase of histone H3 Lys9, mediates 


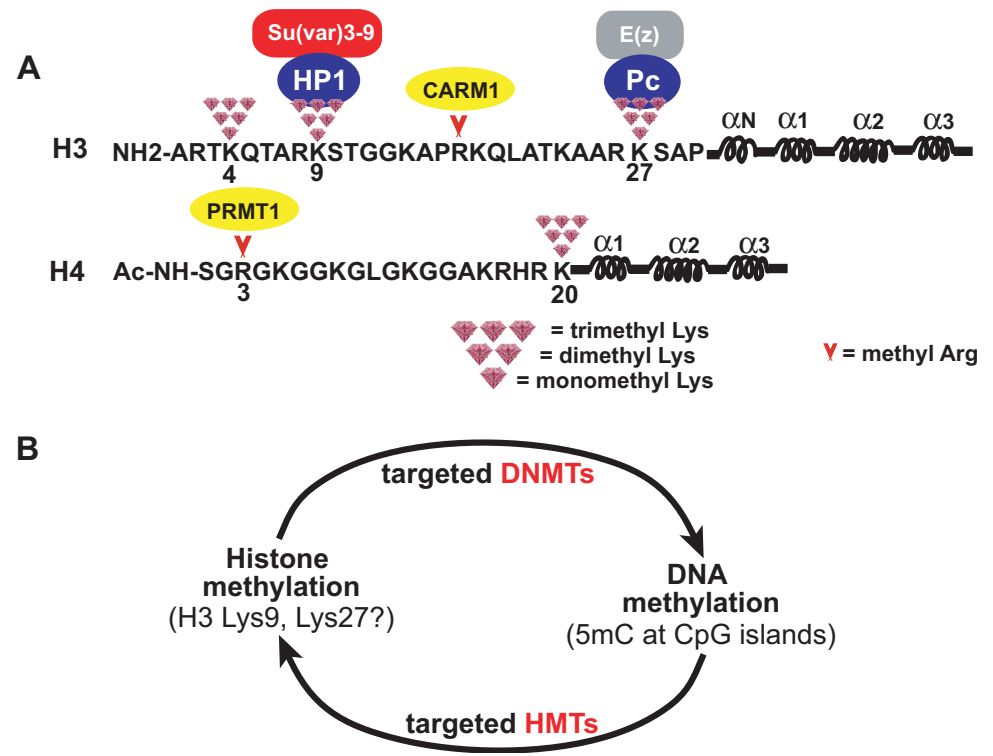

Figure 2. Components of the epigenetic indexing system. $(A)$ Covalent histone modifications, such as methylation of Lys and Arg residues, are marks associated with the genome to indicate gene expression potential of a chromatin region. These marks are "written" by enzymes that covalently modify histones. They exert their function by interacting with binding "effector" proteins, such as HP1, which "reads" H3 Lys9 methyl mark, and polycomb (Pc), which "reads" H3 Lys27 methyl marks. However, without clear binding effector proteins, methyl marks on some histone residues, including H3 Lys4, H4 Lys20, H3 Arg17, and H4 Arg3, remain as "orphan methyl marks." (B) DNA methyl marks and histone methyl marks cross-talk with each other (see text for details). HMT, histone methyltransferase; DNMT, DNA methyltransferase.

DNA methylation (Tamaru et al. 2003). In Arabidopsis thaliana, KRYPTONITE, another histone H3 Lys9 methyltransferase, is also required for DNA methylation (Jackson et al. 2002). These studies suggest a regulatory mechanism whereby DNA methylation is targeted by histone methylation (Fig. 2B).

While the above-mentioned data supports the model that histone methylation guides DNA methylation, other reports suggest that DNA methylation may, in fact, regulate histone methylation as well. For example, DNA hypomethylation due to compromised activity of a maintenance DNA methyltransferase, MET1, causes defects in H3 Lys9 methylation in Arabidopsis thaliana (Soppe et al. 2002). Biochemical studies found that the methylDNA binding protein (MeCP2) interacts with $\mathrm{H} 3$ Lys9 methyltransferase (Fuks et al. 2003). These results suggest that there may be a continous interplay between histone methylation and DNA methylation in certain biological systems. The possibility that DNA methylation may guide histone methylation is especially intriguing in the context of maintaining histone modification patterns following DNA replication.

\section{BASIC CHARACTERISTICS OF EPIGENETIC MARKS: RIGIDITY AND PLASTICITY}

Epigenetic gene expression patterns can be inherited by daughter cells following mitotic and sometimes even meiotic cell division (Cavalli and Paro 1999; Wolffe and Matzke 1999). Therefore, mechanisms must exist to es- tablish and maintain these epigenetic marks in order to faithfully perpetuate gene expression patterns throughout cellular generations.

\section{Establishing the Mark}

What are the signals that establish an epigenetic state on a region of chromatin or on a particular gene? While some of the protein components involved in these pathways have been identified, it is less clear as to (1) how these marks are initially written onto the chromatin template and (2) how a multitude of epigenetic events are temporally coordinated and ordered. Moreover, the "trigger" of a given epigenetic event may vary from case to case.

In genomic imprinting, for example, the difference between two homologous alleles is often their developmental history (i.e., whether the allele is of maternal or paternal origin). During mouse embryonic development, the silencing of maternal or paternal $\mathrm{X}$ chromosome is random in the inner cell mass cells and their descendants. However, in the trophectoderm, the paternal X chromosome is selectively inactivated. Multiple epigenetic events, such as Xist RNA coating and changes in histone-modification patterns, are involved in these two Xinactivation processes (Okamoto et al. 2004).

On the other hand, in Drosophila, the formation of the dosage compensation complex is directly linked with the sex determination process. Translation of male specific lethal 2 (msl2) mRNA is repressed by the sex lethal 
(SXL) protein in females (Kelley et al. 1997). Therefore, the MSL dosage compensation complex is formed to upregulate the gene expression of the single male $\mathrm{X}$ chromosome by twofold. The mechanism of targeting the MSL complex remains poorly understood, but also involves production of noncoding RNAs and histone hyperacetylation (for review, see Park and Kuroda 2001).

In the case of establishing epigenetic marks on an individual gene, the transcriptional status of a given gene seems to determine the downstream epigenetic events. For example, in the process of homeotic gene silencing in Drosophila, the expression pattern is initially established by upstream transcription factors, which is then faithfully maintained in the subsequent development stages by the polycomb group of genes (for review, see Simon and Tamkun 2002). This finding underscores the interesting possibility that the absence of active gene transcription from a specific promoter may trigger downstream epigenetic events as witnessed by a recent study on $\mathrm{p} 16^{\mathrm{INK} 4 \mathrm{a}}$ (Bachman et al. 2003).

\section{Maintaining the Mark}

To impart their functions as epigenetic marks, histone modifications must be maintained during the cell cycle. The paradigm of how DNA methylation marks are propagated during DNA replication and cell division serves as a framework for a discussion on the maintenance of histone modifications, about which much less is known (Jaenisch and Bird 2003). Initial DNA methylation marks are generated by de novo methyltransferases, DNMT3a and DNMT3b. Since DNA methylation is often on the $\mathrm{CpG}$ islands of the DNA double helix, it can be inherited by semiconservative DNA replication. However, after DNA replication, the DNA methylation mark is absent from the newly synthesized daughter strands and therefore could be lost during subsequent rounds of DNA replication. To offset possible dilution effects, the maintenance methyltransferase, DNMT1, methylates the newly synthesized daughter strands of DNA according to the methylation patterns of the parental strands.

However, there are several significant differences in the way that histones are transmitted or inherited as compared to DNA methylation. First, although DNA is wrapped around histones to form the nucleosome, histones can be readily dissociated from DNA during the cell cycle. In extreme cases, such as mammalian spermatogenesis, the majority of histones are removed from the chromatin template and replaced by protamine (SassoneCorsi 2002). Second, DNA methylation is retained on the parental strands after DNA replication, but histone modifications are distributed in a different manner: (1) In $S$ phase, parental histones are distributed randomly onto the two newly duplicated DNA double helices (Wolffe and Matzke 1999 and references therein). Currently, it is not known whether the core histone octamer is incorporated as a whole entity or whether there is some dynamic change of the core histone components. Interestingly, based on biochemical data in Hela cells, a semiconservative nucleosome assembly model was recently proposed (Tagami et al. 2004). (2) Although the majority of histones are deposited into chromatin during $\mathrm{S}$ phase when DNA is replicated, interphase or transcription-associated histone replacement can also occur. For example, the histone H3 variant, H3.3, is actively incorporated into chromatin during interphase (Ahmad and Henikoff 2002).

In sum, mechanisms that govern the inheritance of histones and histone modifications are poorly understood. We suspect that incorporation of histone-modifying enzymes and binding effector proteins may serve to retain the pattern of chromatin marks in much the same way that spreading of heterochromatin, brought about by Lys methylation and HP1 binding, has been proposed to occur (Bannister et al. 2001). Determining how localized enzymatic activities recognize and propagate the patterns of covalent marks to nearby nucleosomes to compensate for the dilution effect of the cell cycle will be an important area of future investigation.

\section{RESETTING EPIGENETIC MARKS IN GERM CELLS AND EARLY EMBRYOS}

Dramatic resetting of the epigenetic marks occurs in germ line cells as well as in preimplantation embryos. DNA methylation marks are first erased and then regenerated during both male and female germ cell development (Hajkova et al. 2002; Lee et al. 2002). Shortly after fertilization, paternal DNA is actively demethylated by an unidentified DNA demethylase, while the maternal DNA methylation pattern is reset passively during subsequent cell divisions (Mayer et al. 2000; Li 2002). However, there are particular loci, especially the imprinted genes, that can escape active DNA demethylation.

Since most histones are replaced by protamine during spermatogenesis, it seems unlikely that the vast majority of "somatic" histone modifications can be transmitted to the next generation through sperm. The maternal genome in the egg, however, does appear to be decorated with a variety of histone modifications whose fate during early development is only beginning to be examined. To begin to test the hypothesis that the reprogramming of histone modifications may play a role in activation of the embryonic genome, we investigated global changes in levels of a series of histone tail modifications during oocyte maturation and preimplantation mouse development (Sarmento et al. 2004). We found that certain "static" histone modifications, such as methylation of H3 Lys 9 and H3 Lys 4, appear to be relatively stable epigenetic marks during early development without exhibiting global change in our assays. However, other modifications, such as acetylation of $\mathrm{H} 3$ and $\mathrm{H} 4$ and methylation of H3 Arg 17 and H4 Arg 3, appear to be dynamically regulated. While the significance for the global resetting of histone Arg methylation marks remains unclear, we favor the view that this process may be involved in the dramatic changes in gene expression patterns observed during the egg-toembryo transition. 


\section{HISTONE (PROTEIN) Arg METHYLATION: IS THIS A "PLASTIC" SIGNAL?}

The finding that histone Arg methylation marks are dynamically regulated in early mouse eggs and embryos prompted us to search for enzymatic activities that can remove methyl groups from histone methyl-Arg residues. Although the fate of methyl group on protein Arg is not known, the modified amino acid, methyl-Arg, can be metabolized by dimethylarginine dimethylaminohydrolase (DDAH) to produce citrulline (Cit) and methylamine as reaction products (depicted in Fig. 3A) (Ogawa et al. 1989; Boger 2003). To investigate the possibility that an enzyme(s) exists that can catalyze a similar reaction on protein substrates like that of DDAH, we scanned the database for DDAH homologous proteins using the Fugue sequence-structure homology-analysis program (www-cryst.bioc.cam.ac.uk/fugue). Significant sequence and secondary structure similarity was found between DDAH and peptidylarginine deiminase (hereafter PAD) (Fig. 3B). PADs are a family of enzymes known to covert Arg residues in proteins to Cit via a deimination reaction, releasing ammonium (Vossenaar et al. 2003). There are five isoforms of PADs that have been identified in human and mouse genomes, including PAD1, $-2,-3,-4$, and -6 . Interestingly, several of these enzymes are correlated with genetic diseases, including multiple sclerosis (PAD2) and rheumatoid arthritis (PAD4) (De Keyser et al. 1999; Suzuki et al. 2003).
Relevant to this discussion are recent findings that one of the most abundant polypeptides in the ovulated mouse egg appears to be a novel PAD family member that is specifically expressed in eggs and early embryos (Wright et al. 2003). In addition, PAD4 is also expressed in the nucleus of eggs and early embryos (Y. Wang and S.A. Coonrod, unpubl.). Taken together, these findings have prompted us to begin testing the hypothesis that PADs can regulate histone Arg methylation levels during early mammalian developmental processes.

\section{BACK FROM THE FUTURE: TO WHAT EXTENT DOES THE "CHROMATIN STATE" INFLUENCE CLONING AND CELLULAR DIFFERENTIATION AND DEDIFFERENTIATION?}

As mentioned above, the success of nuclear cloning experiments in mammals provided a "proof of principle" example that cellular differentiation is regulated by epigenetic mechanisms. The steps involved in cellular differentiation are numerous and are associated with a continual refinement of the pools of cellular mRNAs and proteins, thus ultimately allowing the cell to reach a state in which it can successfully carry out its unique physiological functions. During this process, there are many cues that a cell must respond to and interpret in order to decide which differentiation pathway to choose.

A
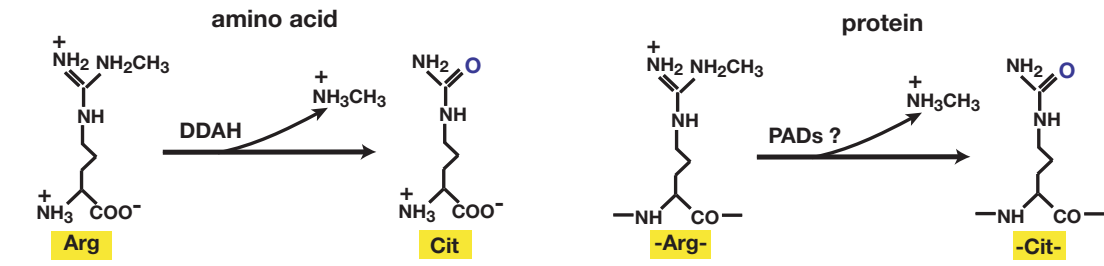

B

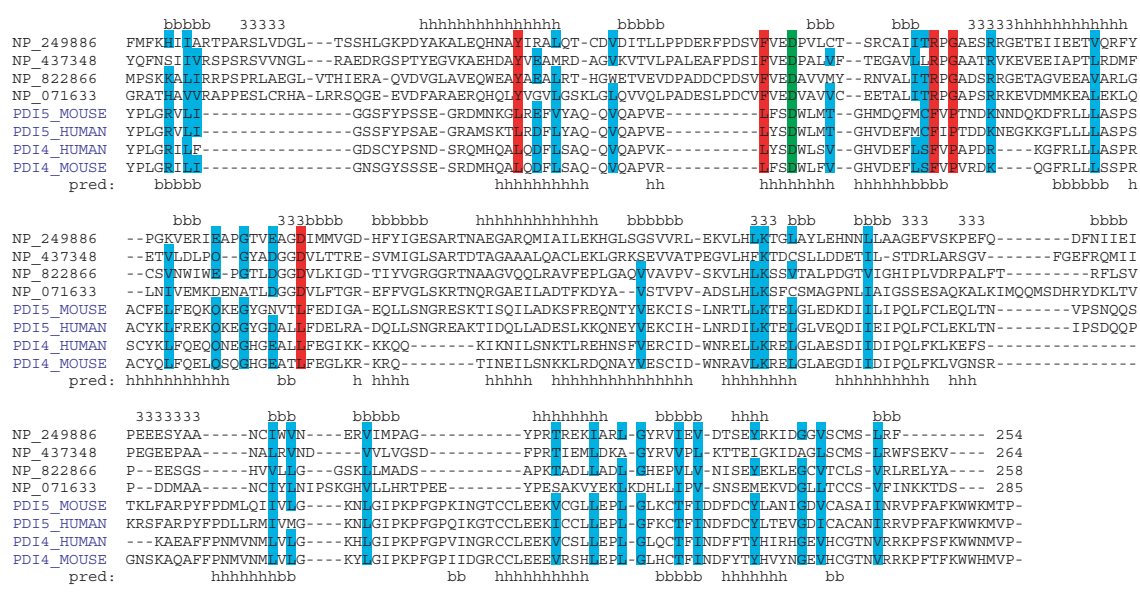

Figure 3. Comparison of DDAH and PAD proteins. $(A)$ The biochemical reaction of dimethylarginine dimethylaminohydrolase (DDAH) on methyl-Arg amino acid and a likely biochemical reaction of peptidylarginine deiminase (PAD) on methyl-Arg residues in proteins. $(B)$ Sequence and structure homology between DDAH and PAD. Identical residues are highlighted by green. Similar residues, such as basic: K, R, H; acidic: D, E; aromatic: F, Y, W, H; beta-branched: T, V, I; aliphatic: L, I, V; hydrogen bonding: C, $\mathrm{S}, \mathrm{T}$; or D/N or EQ, are highlighted in blue. Completely identical residues in both DDAH and PAD families but not identical to each other are highlighted in red. DDAH: NP_249886 (Pseudomonas aeruginosa), NP_437348 (Sinorhizobium meliloti), NP_822866 (Stroptomyces avermitilis), NP_071633 (Rattus norvegicus). 
From an epigenetic viewpoint, we favor the idea that the developmental life history of a cell is engraved on chromatin by posttranslational histone modifications and DNA methylation. If we expand upon and broaden this concept, then in fact all of the structural proteins and enzymes responsible for the generation and maintenance of these epigenetic modifications can also be considered as a part of the "epigenetic information." For example, a certain structure formed on a chromatin region, such as condensed structures on pericentric heterochromatin or silenced homeotic genes, is inherited through cell cycles or memorized by the next generation. Thus, we would like to introduce the concept of "chromatin state," in which DNA and histone modifications interact with their binding or "effector" proteins and affect the local chromatin conformation in order to accommodate different chromatin/DNA templated events, such as transcription (Fig. 4).

Differentiation would be a process of continually refining the chromatin state leading to different sets of gene expression. We can consider the differentiation signals or cues as input, which then leads to the fine adjustment of the chromatin state in a process of "editing" and "writing." The adjustment of the chromatin state can bring about changes from state A to state B, leading to cell differentiation during embryonic development. Multiple machineries, such as the transcriptional complexes, would respond to this change of chromatin state, read the epigenetic information on chromatin, and translate it into meaningful biological readouts. Although differentiation has been considered to be a unidirectional commitment, recent data demonstrated that the forced expression of

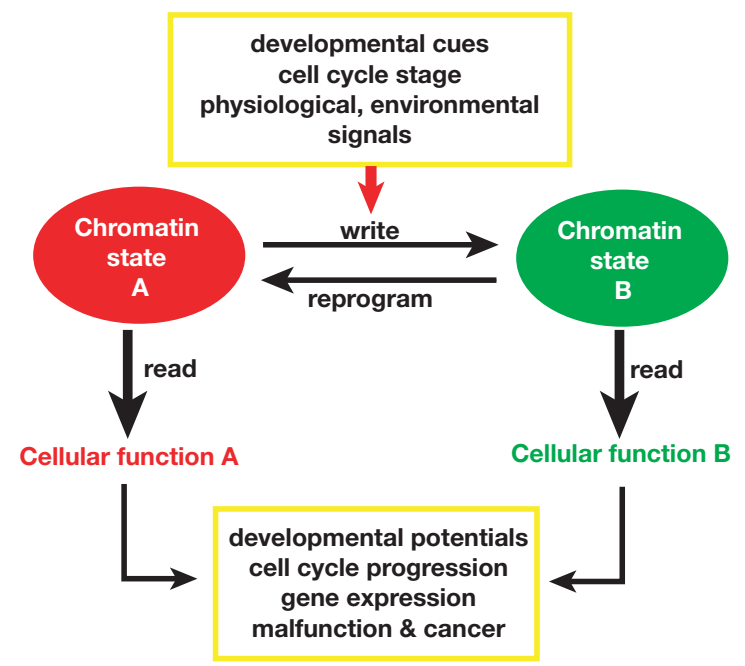

Figure 4. The concept of a chromatin state. The epigenetic information and the binding effector protein of epigenetic marks form an index system of gene expression potentials and regional chromatin conformation that determines a chromatin state. In response to extracellular cues (input), new epigenetic information is "written," and chromatin state "A" can be modified to become chromatin state "B." The change of chromatin state is translated (read) to cellular functions, which underlie(s) various processes such as cell differentiation, gene activity, and etiology of some diseases. Change(s) of chromatin state in the opposite direction (reprogramming) can happen during cloning or dedifferentiation.
$\mathrm{C} / \mathrm{EBP} \alpha$ and $\mathrm{C} / \mathrm{EBP} \beta$ (transcription factors involved in hematopoietic cell differentiation) can reprogram B cells into macrophages, suggesting that the manipulation of upstream master control genes can dramatically change the chromatin state of one cell type into another, thus altering the differentiation pathway (Xie et al. 2004).

In the context of the cloning experiments, the chromatin state in a given cell type, such as a neuron, might be reprogrammed to the primary chromatin state (i.e., the zygote) from which all of the other chromatin states arise (Eggan et al. 2004). The mammalian egg's ability to reprogram terminally differentiated nuclei suggests that eggs have all the machineries required to erase the historic "records" on histones and DNA. New proteomic techniques, combined with the completed human and mouse genome sequences, will likely allow us to identify many of the factors involved in these early steps of development. Ultimately, biochemical and genetic approaches should help us obtain an idea of how these protein components work together to orchestrate this dramatic reprogramming event.

\section{HISTONE METHYLTRANSFERASES AND EPIGENETIC TUMORIGENESIS}

The imbalance of stem cell proliferation and differentiation can lead to cancer. For example, in patients with acute promyelocytic leukemia (APL), promyelocytes keep dividing and fail to differentiate into granulocytes. The ability of all-trans retinoic acid (ATRA) to induce the differentiation of APL cells has offered a successful chemotherapeutic agent to treat APL patients for more than a decade (Fenaux et al. 1992). Therefore, changes of gene expression profiles and epigenetic histone modifications in response to ATRA switch a "cancer" chromatin state to another chromatin state of a short-lived granulocyte. In the following discussion, we will focus on the epigenetic aspect of tumorigenesis.

Enzymes that modify different Lys sites in $\mathrm{H} 3$ have numerous links with human cancers. For example, human MLL1 (also termed ALL1, HRX, or HTRX) has been shown to methylate H3 Lys4 (Milne et al. 2002; Nakamura et al. 2002). The translocations and fusions of MLL1 with dozens of other genes result in acute leukemia. It is intriguing to speculate that MLL normally functions as a tumor "epigenetic" suppressor (see Fig. 5). Chromosome translocations between the mll locus and many other loci result in the loss of the SET domain of MLL. Therefore, the set of genes epigenetically regulated by MLL through marking/indexing with H3 Lys4 methylation is perturbed, which might led to carcinogenesis. The lacking of the H3 Lys9 methyltransferases, Suv39h1 and -2, in mice leads to telomere abnormalities, chromosome instability, and increased rate of B cell lymphomas (Peters et al. 2001). Although the effect on chromosome instability and telomere length should be well considered, we speculate an epigenetic gene-regulation mechanism similar to that of MLL underlying the high incidence of B cell lymphoma. Interestingly, RIZ1, a Rb interacting H3 Lys9 methyltransferase, has been well characterized as a tumor suppressor 
A

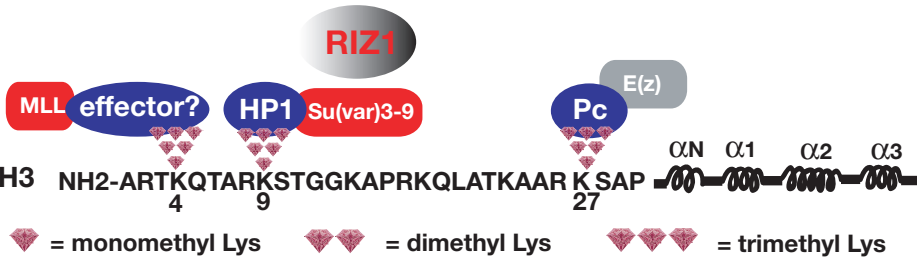

B

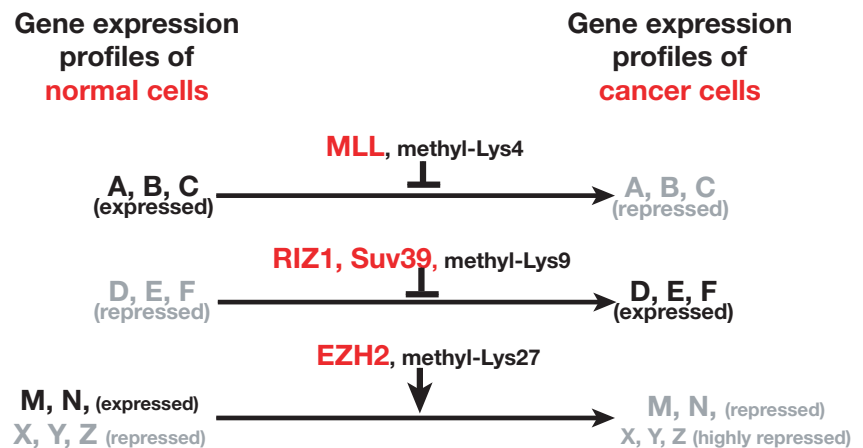

Figure 5. Histone Lys methyltransferases and epigenetic cause of tumorigenesis. (A) In this model, MLL (targeting Lys4), RIZ1, and Su(var)3-9 (targeting Lys9) are considered as tumor "epigenetic" suppressors. Members of the E(z) pathway (EZH2, Bmi1) are considered as "epigenetic" oncogenes. (B) MLL marks the expression potential of genes (A, B, C) by methylation of H3 Lys4 in normal cells. Loss of the normal function of MLL by chromosome translocations causes the repression of these genes thereby inducing cancers. On the other hand, RIZ1 and Su(var)3-9 index the silencing of their target genes (D, E, F); the loss of the repressive marks (H3 Lys9 methylation) leads to overexpression of these genes, thus leading to carcinogenesis. In contrast, the $\mathrm{E}(\mathrm{z})$ pathway maintains the cell proliferation potential by silencing a set of genes (X, Y, Z). The ultra-active $\mathrm{E}(\mathrm{z})$ function can cause cancers either by super-silencing of its target genes $(X, Y, Z)$ or by silencing a new set of genes $(\mathrm{M}, \mathrm{N})$, which is normally expressed to prevent cancer development

(Kim et al. 2003). The low expression and point mutations of RIZ1 are correlated with various human cancers, including breast cancer, liver cancer, colon cancer, neuroblastoma, melanoma, lung cancer, and osteosarcoma, suggesting that RIZ1 may suppress tumorigenesis via an epigenetic mechanism to ensure gene expression profiles of normal cells (Steele-Perkins et al. 2001).

On the other hand, human H3 Lys27 methyltransferase EZH2 was often overexpressed in metastatic prostate cancer and Hodgkin and non-Hodgkin B cell lymphoma (van Kemenade et al. 2001; Varambally et al. 2002). Similarly, Bmi-1, the human homolog of Drosophila Psc, which was shown to regulate the proliferative capacity of normal and leukemic stem cells, is upregulated in cancer cells (Lessard and Sauvageau 2003; Molofsky et al. 2003). Therefore, the EZH2 complex may be overexpressed in cancer cells to hyperrepress cell cycle inhibitor genes, thereby promoting tumorigenesis in a manner like an "epigenetic" oncogene.

In summary, proteins controlling epigenetic gene expression are important regulators of normal cell division, and differentiation, as well as tumorigenesis. We and others favor the idea that histone- and chromatin-modifying enzymes represent excellent targets for exploring pharmaceutical compounds to counteract cancers and other epigenetic disorders (Huang 2002).

\section{ACKNOWLEDGMENTS}

The authors would like to thank members of the Allis lab (The Rockefeller University), and Drs. X. Zhang and
X. Chen (Emory University) for insightful discussions and comments. We appreciate Dr. F. Campagne's help on bioinformatical analyses of PAD4 and DDAH. We thank Upstate Biotech. Inc. for antibody development. Works discussed here are supported by a NIH MERIT Award GM R01 50659 (C.D.A.) and funding provided by The Rockefeller University (C.D.A.), NIH grant R01 HD38353 (S.A.C.), and Damon Runyon Cancer Research Foundation Fellowship (J.W.).

\section{REFERENCES}

Agalioti T., Chen G., and Thanos D. 2002. Deciphering the transcriptional histone acetylation code for a human gene. Cell 111: 381

Ahmad K. and Henikoff S. 2002. The histone variant H3.3 marks active chromatin by replication-independent nucleosome assembly. Mol. Cell 9: 1191.

An W., Kim J., and Roeder R.G. 2004. Ordered cooperative functions of PRMT1, p300, and CARM1 in transcriptional activation of p53. Cell 117: 735.

Bachman K.E., Park B.H., Rhee I., Rajagopalan H., Herman J.G., Baylin S.B., Kinzler K.W., and Vogelstein B. 2003. Histone modifications and silencing prior to DNA methylation of a tumor suppressor gene. Cancer Cell 3: 89 .

Bannister A.J., Schneider R., and Kouzarides T. 2002. Histone methylation: Dynamic or static? Cell 109: 801.

Bannister A.J., Zegerman P., Partridge J.F., Miska E.A., Thomas J.O., Allshire R.C., and Kouzarides T. 2001. Selective recognition of methylated lysine 9 on histone H3 by the HP1 chromo domain. Nature 410: 120.

Bauer U.M., Daujat S., Nielsen S.J., Nightingale K., and Kouzarides T. 2002. Methylation at arginine 17 of histone H3 is linked to gene activation. EMBO Rep. 3: 39. 
Boger R.H. 2003. Asymmetric dimethylarginine ADMA modulates endothelial function-therapeutic implications. Vasc. Med. 8: 149 .

Campbell K.H., McWhir J., Ritchie W.A., and Wilmut I. 1996. Sheep cloned by nuclear transfer from a cultured cell line. $\mathrm{Na}$ ture 380: 64.

Cavalli G. and Paro R. 1999. Epigenetic inheritance of active chromatin after removal of the main transactivator. Science 286: 955.

Cheung P., Allis C.D., and Sassone-Corsi P. 2000. Signaling to chromatin through histone modifications. Cell 103: 263.

Daujat S., Bauer U.M., Shah V., Turner B., Berger S., and Kouzarides T. 2002. Crosstalk between CARM1 methylation and CBP acetylation on histone H3. Curr. Biol. 12: 2090.

De Keyser J., Schaaf M., and Teelken A. 1999. Peptidylarginine deiminase activity in postmortem white matter of patients with multiple sclerosis. Neurosci. Lett. 260: 74.

Dodge J.E., Kang Y.K., Beppu H., Lei H., and Li E. 2004. Histone H3-K9 methyltransferase ESET is essential for early development. Mol. Cell. Biol. 24: 2478.

Eggan K., Baldwin K., Tackett M., Osborne J., Gogos J., Chess A., Axel R., and Jaenisch R. 2004. Mice cloned from olfactory sensory neurons. Nature 428: 44 .

Erhardt S., Su I.H., Schneider R., Barton S., Bannister A.J., Perez-Burgos L., Jenuwein T., Kouzarides T., Tarakhovsky A., and Surani M.A. 2003. Consequences of the depletion of zygotic and embryonic enhancer of zeste 2 during preimplantation mouse development. Development 130: 4235.

Feinberg A.P. and Tycko B. 2004. The history of cancer epigenetics. Nat. Rev. Cancer 4: 143.

Felsenfeld G. and Groudine M. 2003. Controlling the double helix. Nature 421: 448

Fenaux P., Castaigne S., Dombret H., Archimbaud E., Duarte M., Morel P., Lamy T., Tilly H., Guerci A., and Maloisel F., et al. 1992. All-transretinoic acid followed by intensive chemotherapy gives a high complete remission rate and may prolong remissions in newly diagnosed acute promyelocytic leukemia: A pilot study on 26 cases. Blood 80: 2176 .

Fischle W., Wang Y., and Allis C.D. 2003. Binary switches and modification cassettes in histone biology and beyond. Nature 425: 475.

Fuks F., Hurd P.J., Wolf D., Nan X., Bird A.P., and Kouzarides T. 2003. The methyl-CpG-binding protein MeCP2 links DNA methylation to histone methylation. J. Biol. Chem. 278: 4035.

Grunstein M. 1997. Histone acetylation in chromatin structure and transcription. Nature 389: 349.

Hagiwara T., Nakashima K., Hirano H., Senshu T., and Yamada M. 2002. Deimination of arginine residues in nucleophosmin/B23 and histones in HL-60 granulocytes. Biochem. Biophys. Res. Commun. 290: 979.

Hajkova P., Erhardt S., Lane N., Haaf T., El-Maarri O., Reik W., Walter J., and Surani M.A. 2002. Epigenetic reprogramming in mouse primordial germ cells. Mech. Dev. 117: 15.

Hiendleder S., Mund C., Reichenbach H.D., Wenigerkind H., Brem G., Zakhartchenko V., Lyko F., and Wolf E. 2004. Tissue-specific elevated genomic cytosine methylation levels are associated with an overgrowth phenotype of bovine fetuses derived by in vitro techniques. Biol. Reprod. 71: 217.

Huang S. 2002. Histone methyltransferases, diet nutrients and tumor suppressors. Nat. Rev. Cancer 2: 469.

Jackson J.P., Lindroth A.M., Cao X., and Jacobsen S.E. 2002. Control of CpNpG DNA methylation by the KRYPTONITE histone H3 methyltransferase. Nature 416: 556.

Jaenisch R. and Bird A. 2003. Epigenetic regulation of gene expression: How the genome integrates intrinsic and environmental signals. Nat. Genet. (suppl.) 33: 245.

Janicki S.M., Tsukamoto T., Salghetti S.E., Tansey W.P., Sachidanandam R., Prasanth K.V., Ried T., Shav-Tal Y., Bertrand E., Singer R.H., and Spector D.L. 2004. From silencing to gene expression: Real-time analysis in single cells. Cell 116: 683.

Jenuwein T. and Allis C.D. 2001. Translating the histone code. Science 293: 1074.

Kelley R.L., Wang J., Bell L., and Kuroda M.I. 1997. Sex lethal controls dosage compensation in Drosophila by a non-splicing mechanism. Nature 387: 195.

Kelly T.L. and Trasler J.M. 2004. Reproductive epigenetics. Clin. Genet. 65: 247.

Khorasanizadeh S. 2004. The nucleosome: From genomic organization to genomic regulation. Cell 116: 259.

Kim J.H., Yoon S.Y., Kim C.N., Joo J.H., Moon S.K., Choe I.S., Choe Y.K., and Kim K.C., Geng L., and Huang S. 2003. Inactivation of a histone methyltransferase by mutations in human cancers. Cancer Res. 63: 7619.

Kouzarides T. 2002. Histone methylation in transcriptional control. Curr. Opin. Genet. Dev. 12: 198.

Kurdistani S.K., Tavazoie S., and Grunstein M. 2004. Mapping global histone acetylation patterns to gene expression. Cell 117: 721.

Lachner M., O'Sullivan R.J., and Jenuwein T. 2003. An epigenetic road map for histone lysine methylation. J. Cell Sci. 116: 2117.

Lee J., Inoue K., Ono R., Ogonuki N., Kohda T., Kaneko-Ishino T., Ogura A., and Ishino F. 2002. Erasing genomic imprinting memory in mouse clone embryos produced from day 11.5 primordial germ cells. Development 129: 1807.

Lessard J. and Sauvageau G. 2003. Bmi-1 determines the proliferative capacity of normal and leukaemic stem cells. Nature 423: 255.

Li E. 2002. Chromatin modification and epigenetic reprogramming in mammalian development. Nat. Rev. Genet. 3: 662

Luger K., Mader A.W., Richmond R.K., Sargent D.F., and Richmond T.J. 1997. Crystal structure of the nucleosome core particle at $2.8 \AA$ resolution. Nature 389: 251.

Matzuk M.M. and Lamb D.J. 2002. Genetic dissection of mammalian fertility pathways. Nat. Cell Biol. (suppl.) 4: s41.

Mayer W., Niveleau A., Walter J., Fundele R., and Haaf T. 2000. Demethylation of the zygotic paternal genome. Nature 403: 501.

Milne T.A., Briggs S.D., Brock H.W., Martin M.E., Gibbs D., Allis C.D., and Hess J.L. 2002. MLL targets SET domain methyltransferase activity to Hox gene promoters. Mol. Cell 10: 1107.

Molofsky A.V., Pardal R., Iwashita T., Park I.K., Clarke M.F., and Morrison S.J. 2003. Bmi-1 dependence distinguishes neural stem cell self-renewal from progenitor proliferation. $\mathrm{Na}$ ture 425: 962.

Nakamura T., Mori T., Tada S., Krajewski W., Rozovskaia T., Wassell R., Dubois G., Mazo A., Croce C.M., and Canaani E. 2002. ALL-1 is a histone methyltransferase that assembles a supercomplex of proteins involved in transcriptional regulation. Mol. Cell 10: 1119.

Ogawa T., Kimoto M., and Sasaoka K. 1989. Purification and properties of a new enzyme, NG,NG-dimethylarginine dimethylaminohydrolase, from rat kidney. J. Biol. Chem. 264: 10205 .

Okamoto I., Otte A.P., Allis C.D., Reinberg D., and Heard E. 2004. Epigenetic dynamics of imprinted X inactivation during early mouse development. Science 303: 644.

Park Y. and Kuroda M.I. 2001. Epigenetic aspects of X-chromosome dosage compensation. Science 293: 1083.

Peters A.H., O'Carroll D., Scherthan H., Mechtler K., Sauer S., Schofer C., Weipoltshammer K., Pagani M., Lachner M., Kohlmaier A., Opravil S., Doyle M., Sibilia M., and Jenuwein T. 2001. Loss of the Suv39h histone methyltransferases impairs mammalian heterochromatin and genome stability. Cell 107: 323 .

Roth S.Y., Denu J.M., and Allis C.D. 2001. Histone acetyltransferases. Annu. Rev. Biochem. 70: 81.

Santos-Rosa H., Schneider R., Bernstein B.E., Karabetsou N., Morillon A., Weise C., Schreiber S.L., Mellor J., and Kouzarides T. 2003. Methylation of histone H3 K4 mediates association of the Isw1p ATPase with chromatin. Mol. Cell 12: 1325 .

Sarmento O.F., Digilio L.C., Wang Y., Perlin J., Herr J.C., Allis C.D., and Coonrod S.A. 2004. Dynamic alterations of specific histone modifications during early murine development. $J$. Cell Sci. 117: 4449. 
Sassone-Corsi P. 2002. Unique chromatin remodeling and transcriptional regulation in spermatogenesis. Science 296: 2176

Schreiber S.L. and Bernstein B.E. 2002. Signaling network model of chromatin. Cell 111: 771

Schubeler D., MacAlpine D.M., Scalzo D., Wirbelauer C., Kooperberg C., van Leeuwen F., Gottschling D.E., O’Neill L.P., Turner B.M., Delrow J., Bell S.P., and Groudine M. 2004. The histone modification pattern of active genes revealed through genome-wide chromatin analysis of a higher eukaryote. Genes Dev. 18: 1263.

Shiio Y. and Eisenman R.N. 2003. Histone sumoylation is associated with transcriptional repression. Proc. Natl. Acad. Sci. 100: 13225 .

Simon J.A. and Tamkun J.W. 2002. Programming off and on states in chromatin: Mechanisms of Polycomb and trithorax group complexes. Curr. Opin. Genet. Dev. 12: 210.

Soppe W.J., Jasencakova Z., Houben A., Kakutani T., Meister A., Huang M.S., Jacobsen S.E., Schubert I., and Fransz P.F. 2002. DNA methylation controls histone $\mathrm{H} 3$ lysine 9 methylation and heterochromatin assembly in Arabidopsis. EMBOJ. 21: 6549 .

Steele-Perkins G., Fang W., Yang X.H., Van Gele M., Carling, T., Gu J., Buyse I.M., Fletcher J.A., Liu J., Bronson R., Chadwick R.B., de la Chapelle A., Zhang X., Speleman F., and Huang S. 2001. Tumor formation and inactivation of RIZ1, an $\mathrm{Rb}$-binding member of a nuclear protein-methyltransferase superfamily. Genes Dev. 15: 2250.

Strahl B.D. and Allis C.D. 2000. The language of covalent histone modifications. Nature 403: 41.

Strahl B.D., Ohba R., Cook R.G., and Allis C.D. 1999. Methylation of histone $\mathrm{H} 3$ at lysine 4 is highly conserved and correlates with transcriptionally active nuclei in Tetrahymena. Proc. Natl. Acad. Sci. 96: 14967.

Strahl B.D., Briggs S.D., Brame C.J., Caldwell J.A., Koh S.S., Ma H., Cook R.G., Shabanowitz J., Hunt D.F., Stallcup M.R., and Allis C.D. 2001. Methylation of histone H4 at arginine 3 occurs in vivo and is mediated by the nuclear receptor coactivator PRMT1. Curr. Biol. 11: 996.

Strukov Y.G., Wang Y., and Belmont A.S. 2003. Engineered chromosome regions with altered sequence composition demonstrate hierarchical large-scale folding within metaphase chromosomes. J. Cell Biol. 162: 23.

Suzuki A., Yamada R., Chang X., Tokuhiro S., Sawada T., Suzuki M., Nagasaki M., Nakayama-Hamada M., Kawaida R., Ono M., Ohtsuki M., Furukawa H., Yoshino S., Yukioka M., Tohma S., Matsubara T., Wakitani S., Teshima R., Nishioka Y., Sekine A., Iida A., Takahashi A., Tsunoda T., Nakamura Y., and Yamamoto K. 2003. Functional haplotypes of
PADI4, encoding citrullinating enzyme peptidylarginine deiminase 4 , are associated with rheumatoid arthritis. Nat. Genet. 34: 395.

Tagami H., Ray-Gallet D., Almouzni G., and Nakatani Y. 2004. Histone H3.1 and H3.3 complexes mediate nucleosome assembly pathways dependent or independent of DNA synthesis. Cell 116: 51.

Tamaru H., Zhang X., McMillen D., Singh P.B., Nakayama J., Grewal S.I., Allis C.D., Cheng X., and Selker E.U. 2003. Trimethylated lysine 9 of histone $\mathrm{H} 3$ is a mark for DNA methylation in Neurospora crassa. Nat. Genet. 34: 75.

van Holde K.E. 1989. Chromatin. Springer-Verlag, New York. van Kemenade F.J., Raaphorst F.M., Blokzijl T., Fieret E., Hamer K.M., Satijn D.P., Otte A.P., and Meijer C.J. 2001. Coexpression of BMI-1 and EZH2 polycomb-group proteins is associated with cycling cells and degree of malignancy in B-cell non-Hodgkin lymphoma. Blood 97: 3896.

Varambally S., Dhanasekaran S.M., Zhou M., Barrette T.R., Kumar-Sinha C., Sanda M.G., Ghosh D., Pienta K.J., Sewalt R.G., Otte A.P., Rubin M.A., and Chinnaiyan A.M. 2002. The polycomb group protein EZH2 is involved in progression of prostate cancer. Nature 419: 624

Vossenaar E.R., Zendman A.J., van Venrooij W.J., and Pruijn G.J. 2003. PAD, a growing family of citrullinating enzymes: Genes, features and involvement in disease. Bioessays 25: 1106.

Wakayama T., Perry A.C., Zuccotti M., Johnson K.R., and Yanagimachi R. 1998. Full-term development of mice from enucleated oocytes injected with cumulus cell nuclei. Nature 394: 369 .

Wang H., Huang Z.Q., Xia L., Feng Q., Erdjument-Bromage H., Strahl B.D., Briggs S.D., Allis C.D., Wong J., Tempst P., and Zhang Y. 2001. Methylation of histone H4 at arginine 3 facilitating transcriptional activation by nuclear hormone receptor. Science 293: 853.

Wolffe A. 1998. Chromatin. Academic Press, London.

Wolffe A.P. and Matzke M.A. 1999. Epigenetics: Regulation through repression. Science 286: 481.

Wright P.W., Bolling L.C., Calvert M.E., Sarmento O.F., Berkeley E.V., Shea M.C., Hao Z., Jayes F.C., Bush L.A., Shetty J., Shore A.N., Reddi P.P., Tung K.S., Samy E., Allietta M.M., Sherman N.E., Herr J.C., and Coonrod S.A. 2003. ePAD, an oocyte and early embryo-abundant peptidylarginine deiminase-like protein that localizes to egg cytoplasmic sheets. Dev. Biol. 256: 73.

Xie H., Ye M., Feng R., and Graf T. 2004. Stepwise reprogramming of B cells into macrophages. Cell 117: 663 .

Zhang Y. and Reinberg D. 2001. Transcription regulation by histone methylation: Interplay between different covalent modifications of the core histone tails. Genes Dev. 15: 2343. 


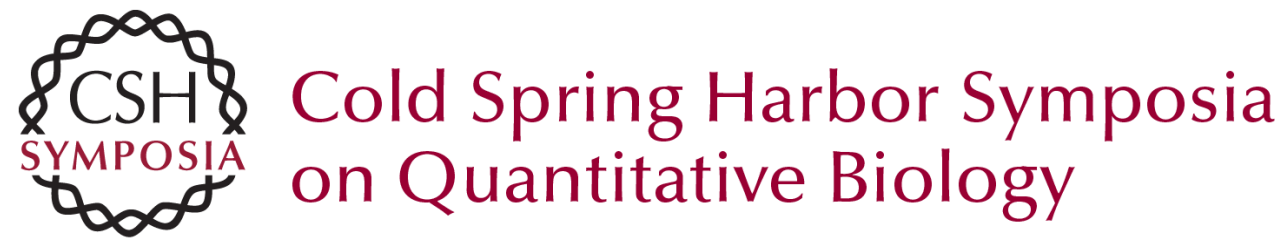

\title{
Linking Covalent Histone Modifications to Epigenetics: The Rigidity and Plasticity of the Marks
}

\author{
Y. WANG, J. WYSOCKA, J.R. PERLIN, et al. \\ Cold Spring Harb Symp Quant Biol 2004 69: 161-170 \\ Access the most recent version at doi:10.1101/sqb.2004.69.161
}

References This article cites 76 articles, 24 of which can be accessed free at: http://symposium.cshlp.org/content/69/161.full.html\#ref-list-1

\section{License}

Email Alerting

Receive free email alerts when new articles cite this article - sign up in Service the box at the top right corner of the article or click here. 